Research Article/Araştırma Makalesi

\title{
Undergraduate Students' Perceptions Regarding the Environment: Discuss, Draw, and Write Down
}

\author{
Özgür TAŞKIN *1 (D) Merve Gül KÜLCÜ 2 (i) \\ ${ }^{1}$ Ondokuz Mayıs University, Faculty of Education, Samsun, Turkey, otaskin@omu.edu.tr \\ ${ }^{2}$ Ondokuz Mayıs University, Faculty of Education, Samsun, Turkey, merve.kulcu@outlook.com \\ *Corresponding Author: otaskin@omu.edu.tr
}

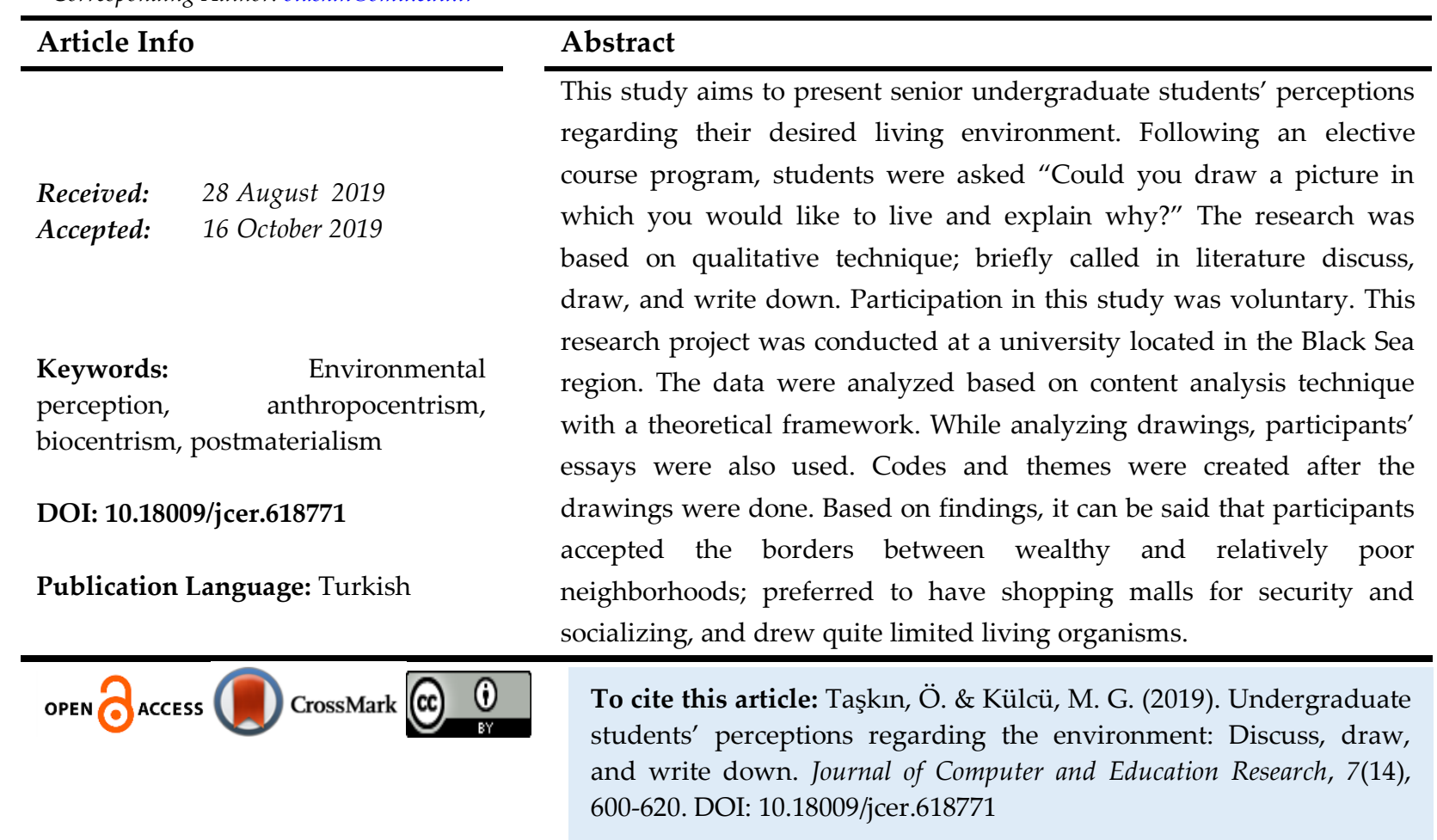

\section{Lisans Öğrencilerinin Çevre Algıları Üzerine: Tartış, Çiz ve Yaz}

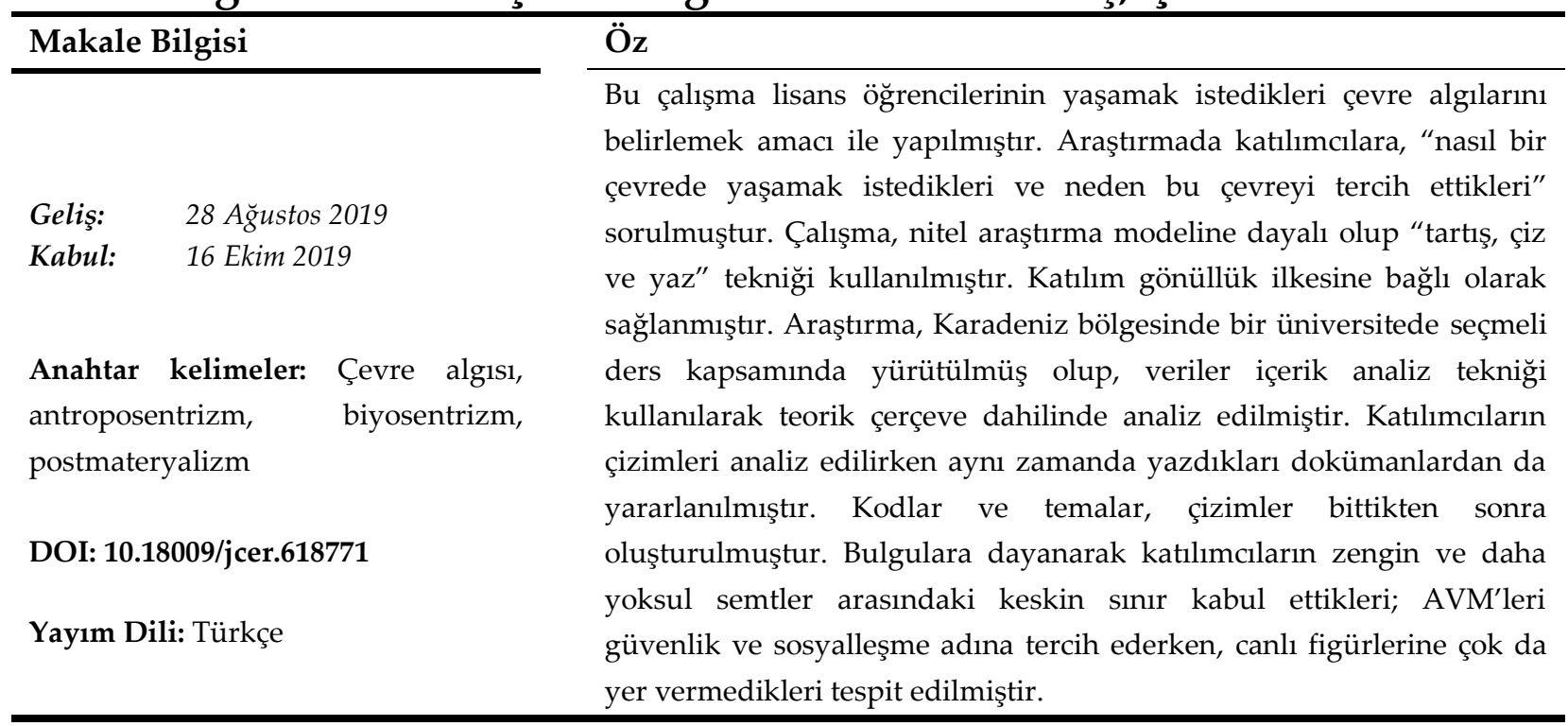




\title{
Summary
}

\section{Undergraduate Students' Perceptions Regarding the Environment: Discuss, Draw, and Write Down}

\begin{abstract}
Introduction
Environmental education (EE) studies and debates over previously conducted EE research are abundant. Most conflicts regarding EE research have emerged from methodological problems, lack of theoretical framework, epistemology, and philosophical background (Hart \& Nolan, 1999). Outdoor education, attitude \& perception studies and such topics are quite rich. This study aims at presenting students' perceptions regarding their desired living sphere. Basically, students are asked "Could you draw a picture in which you would like to live and explain why?" Indeed, most studies show that people would like to have open space, live near recreational area and have different tones of comfort. However, such cliché phrases are not part of the present study. This research differs in particularly two ways. First, findings are analyzed based on unified theoretical frameworks and some other scaffolding terms. These are Postmaterialist Theory, New Environmental Paradigm, Dominant Social Paradigm, anthropocentrism, and biocentrism. Second, the codes and themes are defined after drawings are done. From this perspective, inductive and deductive approaches nurture each other in the present study. At the same time terms such as biocentrism and its perception by participant are reviewed.
\end{abstract}

\section{Method}

This research project was conducted at a university located in the Black Sea region in Turkey. The data were gathered in a course in 2015-2016 spring semesters. The participants were senior students $(\mathrm{N}=50)$. The research was based on qualitative technique; briefly called in literature discuss, draw, and write down. Participation in this study was voluntary. Sampling type was convenience one (Patton 2014). After thirteen-week course program, the data were collected. The course content knowledge was presented in evidence-based 
interactive lecture. After the course program was done, participants worked in a group based on to discuss, draw, and write down.

The data were analyzed based on content analysis technique (Yıldırım \& Şimşek, 2008 p. 228). While analyzing drawings, participants' essays were also used. Codes and themes were created after drawings were done. More clearly, created codes and themes were based on the nature of qualitative research technique: Inductive (Patton, 2014). However, at the same time, data were analyzed based on Postmaterialist theoretical framework with the help of Anthropocentrism-Biocentrism and New Environmental Paradigm (NEP)-Dominant Social Paradigm (DSP) dichotomies which were based on deductive approach. Both use of two approaches, taking into account of all codes, and checking codes-themes by two researchers were the most important parts of validity and reliability issues (Yıldırım \& Şimşek, 2008, p. 259).

\section{Results}

Drawing themes were gathered under 3 titles. These titles were boiled down under natural areas, alive elements, and artificial areas. According to the results, alive elements were considerably limited in drawings. Even though living organisms in the drawings might be regarded as a biocentric point of view, these elements were mostly based on participants' needs.

Participants drawings showed that shopping malls were indispensable part of their life. Their choices were based on some reasons which were easy transportation, socialization zone, and security. From all aforementioned theoretical frameworks, participants' tendencies might not be classified biocentric or eco-friendly. Strict borders between neighborhoods were the choice of participants. Most of them consciously or not accepted the existence poor and rich neighborhood. Again, high constructions with security forces and villas for rich people segregated from other poor neighborhoods were some of the most significant findings. Gathering with friends based on lifestyle in shopping malls, socio-cultural differences, status of people and such parameters were represented in drawings.

\section{Discussion and Conclusion}

Since the research technique was based on qualitative and the sampling size was limited, the results cannot be generalized. Even though the data were gathered from a local university, student diversity helped to have a clear picture regarding research topic. 
Based on theoretical frameworks, participants might not be considered proenvironmentalist. For instance, shopping mall was regarded as social activity zone because of security and easy transportation. In addition, theater, library and such cultural concepts were quite invisible compared to shopping mall.

Interestingly, participants' drawings showed that the neighborhood borders were strict. This looked like acceptation of class and status differences by participants. This might be deemed as the signal of segregation: Rich from the others generally the poorer. These results were interesting while considering "Could you draw a picture in which you would like to live...?" question. The acceptance of ghettoization can be elaborated in another research based on environmental values. In this sense, Brundtland Report's most neglected part "equality" should be reconsidered.

Even though most of the studies considered the participants as biocentric, this socalled biocentric tendency could be deemed as more pragmatic explanation. In the present research, living organism figures were highly limited and mostly animals were sheep and such needed domesticated one.

Participants' most important perception regarding living zone was security. It can be concluded that participants cannot be considered pro-environmentalist based on the NEP and postmaterialist values. It should be noted that acculturation, social security, parents' education levels should be taken into account in upcoming EE studies. And certainly, the effective EE program should be implemented. Hopefully, research findings will motivate other environmental educators to conduct new research and fill the gap in this study. 


\section{Giriş}

Çevre eğitimi (ÇE) alanında, tutum, davranış, mekân dışı eğitim gibi çalışmalar ve bu çalışmalar üzerine tartışmalar son derece yoğundur. Örneğin, Ramsey ve Rickson (1976) çalışmalarında çevre bilgisinin, çevreye karşı olumlu davranış geliştirmek için yeterli olmadığını vurgularken; çevre okuryazarlığının da kısa dönem uygulamalarla sağlanamayacağına işaret etmektedirler. Bu noktada mekân dişı öğrenim (outdoor education) adı altında yapılan onlarca çalışmanın sonuçları ise okuyucuya bırakılmaktadır. Mekân dışı eğitimde hazırlanan programlarda herhangi bir teorik çerçeve yoksa ya da epistemik pratikler yeterli değilse sonuçların kalıcı olmasını beklemek naif bir yaklaşımdır. Kaldı ki, öğretim pratiklerinin sistematik ve düzenli olması da çevre duyarlılığı olan bireyler yetiştirmek için yeterli olmayabilir. Örneğin, 'nasıl bir ortamda yaşamak istiyorum' sorusuna bireylerin değişik yanıtlar vermesi şaşırtıcı değildir (Taşkın, 2016). Bireylerin yanıtları genel olarak, insan merkezli (antroposentrik) ve canlı merkezli (biyosentrik) olmak üzere iki başlıkta sınıflandırılabilir. Kişilerin dualistik karakter sergilemesi de mümkündür. Örneğin, nasıl bir çevrede yaşamak istenildiği sorulduğunda muhtemel yanıtlar daha yeşil, suya yakın, hatta betonlaşmanın olmadığı bir ortam olabilir. Bunun yanı sıra "huzur ve refah içerisinde yaşamak istiyorum" tarzında muğlak ifadeler duymak olasıdır. Ancak böyle bir ortama katkıları var mı? Böyle bir çevrede yaşamak için toplumsal ya da bireysel bir çabaları bulunmakta mı? Tüm bu sorulara kolaylıkla yanıt vermek olası değildir. Bu çalışmada ise lisans öğrencilerinin "nasıl bir çevrede yaşamak istiyorsunuz?" sorusuna ilişkin resimler çizmeleri istenmiş ve çizilen resimler üzerinden araştırmacılar katılımcıların arzu ettikleri çevre algısını teorik çerçeve üzerinden yorumlamışlardır. Çalışma hem durum tespiti (betimleyici) hem de durumun kuramsal açıdan irdelenmesine dayanmaktadır. Kısaca araştırmada "öğrenciler çiçekleri çok sevmektedir" ya da "yeşil alana önem vermektedir" gibi betimleyici klişe ifadeler bulunmamaktadır.

ÇE ile ilgili alan yazın incelendiğinde, farklı yaş gruplarının algıladıkları çevre sorunları ve buna bağlı olarak geliştirdikleri tutum, davranış, algı, bilgi vb. konular üzerine odaklanıldığı görülmektedir. Antroposentrizm/biyosentrizm kavramları ile ilgili literatürler incelendiğinde; Erten ve Aydoğdu (2011) yaptıkları çalışmada, Türk ve Azerbaycanlı öğretmen adaylarının çevreye karşı tutumlarını insan merkezli, canlı merkezli ve antipatik tutumlar olmak üzere 3 farklı boyutta değerlendirmiştir. Araştırma sonucunda katılımcıların büyük bir kısmının canlı merkezli yaklaşıma yatkın olduğu vurgulanmaktadır. Benzer 
şekilde Karakaya ve Çobanoğlu da (2012) araştırmalarında, katılımcıların \%85'inin canlı merkezli tutumu benimsediğini iddia etmektedir. Çok benzer bir uygulama Bozdemir ve Faiz (2018) tarafından yürütülmüştür. Bozdemir ve Faiz'in araştırmalarında öğretmen adaylarının çevre merkezli tutuma sahip oldukları sonucuna ulaşılmıştır. Çalışmalarda demografik değişkenler olarak cinsiyet, sınıf düzeyi ve öğrenim programlarının özellikleri (yapılandırmacı vs.) kullanılmaktadır. İlginç bir şekilde araştırmaların çoğunda gelecek açısından katılımcıların çevreye karşı tutumlarının olumlu olduğu iddia edilmektedir. Erten ve Aydoğdu bu ve benzeri olumlu araştırma sonuçların altında yatan gerekçenin, doğanın insan için korunması gerekliliği düşüncesine dayalı olma olasılığı üzerinde durmaktadır. Bu da son derece pragmatik, doğal olarak da insan merkezli bir yaklaşımın hâkim olduğunu göstermektedir. Bu düşünceyi destekler nitelikte Özen-Uyar ve Yılmaz (2016) okul öncesi çocukların çevre tutumlarını inceledikleri çalışmada katılımcıların ekosentrik tutumlar sergilediklerini tespit etmiştir. Ancak bu ekosentrik yaklaşımın ardında antroposentrik tutum olduğunu belirtmişlerdir.

ÇE alanında yapılan çizim çalışmalarına baktığımızda ise, Taşkın ve Şahin (2008) okul öncesi çocukların çevre algılarının, yaşadıkları yere ve sosyoekonomik düzeye göre farklı şekillerde geliştiğini ortaya koymaktadır. Benzer şekilde, Halmatov, Sarıçam ve Halmatov (2012) çalışmalarında katılımcıların sosyo-ekonomik düzeylerine göre çevre algılarının farklılaştığı sonucuna ulaşmışlardır. Özsoy ve Ahi (2014) çalışmalarında farklı illerden ilkokul öğrencilerinin "gelecekte nasıl bir çevre beklentisi içinde olduklarını" incelemişlerdir. Çalışma sonucuna göre, kırsal bölgede yaşayan öğrenciler gelecekteki çevrenin daha temiz olacağını tahayyül etmektedirler. Katılımcıların yaşları arttıkça çevrenin kirletildiği üzerine algınında arttı̆̆ı gözlenmiştir. Özden ve Özden (2015) ortaokul öğrencilerinin çevre sorunları algılarını çizim yoluyla incelemişlerdir. Çalışmada katılımcıların küresel çevre sorunlarının farkında olduğu sonucuna ulaşılmıştır. Pınar ve Yakışan (2017) ise ilkokul öğrencilerinin çevre kirliliği algılarını inceledikleri araştırmada, katılımcıların çoğunun çevre kirliliğini çöp sorununa dayandırdığı sonucuna ulaşmışlardır. Yavuz, Balkan Kıyıcı ve Atabek-Yiğit (2015) ortaokul öğrencilerinin çizimlerinde canlı öğelere yapay öğelerden daha çok yer verdiklerini belirlemişlerdir. Pınar ve Yakışan’ın çalışmasına benzer şekilde katılımcılar, çöplerin en belirgin çevre kirliliği kaynağı olduğu düşüncesindedirler. Işık ve Çetin (2014) 11. sinıf öğrencilerinin yaşadıkları çevreye ilişkin görüşlerini inceledikleri çalışmada katılımcıların içinde bulundukları çevreyi orta derecede temiz ya da temiz buldukları sonucuna 
ulaşmışlardır. Katılımcıların çoğunun yerel çevre sorunlarına odaklandıkları ve çevre kirliliğinin daha çok belediyenin dolayısıyla devletin sorumluluğunda olduğunu düşünmektedirler. Barraza (1999) 7-9 yaş arası İngiliz ve Meksikalı öğrencilerin çevresel kaygılarını incelemiştir. Araştırmasında Meksikalı ve İngiliz öğrenciler arasında önemli yapısal ve kültürel fark olmasına karşın katılımcıların çoğunun benzer çevresel kaygılar içerisinde olduğunu gözlemlemiştir. Barraza sonuçların iki öğrenci grubunda farklılık göstermemesini, katılımcıların benzer sosyo-ekonomik düzeylerine sahip olmalarına, benzer yaşam alanlarında yaşamalarına ve bilgiye erişimin benzer olmasına dayandırmaktadır. Fleer (2002), 5-12 yaş grubu öğrencilerin gelecekteki çevre hakkındaki görüşlerini incelemiştir. Araştırmada katılımcıların çoğunun gelecekteki çevre sorunları için olumsuz bir perspektif çizdiği sonucuna ulaşmıştır. Alerby (2000) “çevre kelimesini hakkında ne düşünüyorsunuz?" sorusu ile katılımcıların çevre algısını fenomonoloji yöntemiyle incelemiş olup dört tema oluşturmuştur. Bunlar; iyi dünyaya (temiz çevreye) odaklanan düşünceler, kötü dünyaya (kirli çevreye) odaklanan düşünceler, iyi ve kötü dünya arasındaki düşünceler ve çevre koruma eğilimindeki düşüncelerdir. Alerby katılımcıların \%50si iyi dünyaya yani temiz çevre düşüncesine odaklandığı sonucuna ulaşmıştır. Fakat bu sonucun büyük bir kısmını somut dönem çocukların kapsadığını, yaşın ilerlemesiyle küresel bir bakışa sahip olduğunu belirtirken, çizimlerin çoğunun antroposentrik anlayışa sahip olduğunu ifade etmiştir.

Genel anlamda çevre tutum, davranış ve algı çalışmalarına bakıldığında nasıl ve neden sorusuna yanıt verilemediği görülmektedir. Taşkın ve Külcü (2019) çalışmalarda oluşan bu boşluğun önemli bir nedeninin araştırmaların teorik çerçevesinden kaynaklandığını belirmektedirler. Bu çalışmanın önemli bir özelliği de daha önce uygulanan birçok alan yazın çalışmalarının aksine kuramsal bir çerçevesinin olmasıdır. Ele alınan araştırma sorusu ile önemli derecede ilişkili olduğu varsayılan faktörlerin tümü arasındaki ilişkiyi ortaya koymak açısından teorik çerçeve varlığı önemlidir. Aşağıda bu çalışmada kullanılan teorik çerçeveye ve kavramlara ilişkin tanımlamalar bulunmaktadır.

\section{Postmateryalizm}

İkinci Dünya Savaşı sonrası kıta Avrupa ve Britanya toplumlarının yaşamlarını sürdürmekle ilgili endişeleri azalmış olup ve geçmişte var olan yaşam güvencesi korkusu yerine yaşama ilişkin daha farklı değerler geliştirmeye başlamışlardır. Inglehart (1977) bu 
süreci, insanların makul düzeyde ekonomik güvence ve bolluğa ulaşırken kendilerini gerçekleştirip farklı değerler geliştirmeleriyle ilişkilendirmiştir. İfade özgürlüğü, bireysel eşitlik ve çevre bilinci gibi konular insanların yaşamına giren postmateryalist değerlerden bazılarıdır. Özetle Inglehart, bireylerin yaşamlarındaki önceliklerini değiştirdiklerini ve farklı değerlere doğru geçiş yaşadıklarını belirtmektedir. Inglehart’a göre toplumda bu değerlere sahip olmaya başlayan bireylerin genellikle ekonomik anlamda az sorun yaşayan ve nüfusun orta-üst kesimi ve gençlerinden oluştuğunu ifade edilmektedir. Bu toplumsal kesimin, özellikle öğrenim düzeyi yüksek ve Weberyan tanımla orta sinıf bireylerden oluştuğunun istatistiğini sunmuştur. Bu değerler bütününü ise "post-materyalist değerler" olarak tanımlamaktadır. Inglehart'ın bu kuramsal çerçevesine göre gelir seviyesi düşük ya da son derece yüksek olan kitlelerin çevre koruma eğilimleri daha az olacağı sonucu karşımıza çıkmaktadır. Inglehart'ın bu yaklaşımına karşın Martinez-Alier (2002, s.4) "The Environmentalism of the Poor" (Yoksulların Çevreciliği) adlı kitabında 1970 sonrası çevre bilinci gelişiminin bireylerin refah seviyesinin artışıyla birlikte gelen kendini gerçekleştirme olgusuyla ilişkili olmadığını; bu bireylerin sanayileşme sonrası artan kimyasal vb. kirlilikten doğan kaygılarından kaynaklandığını belirtmiştir. Yoksulların çevreciliğini; yerli halkın yaşadıkları yerlerde olası tehlikeye karşı verdikleri mücadeleyi içermekte olduğunu ileri sürmektedir (Martinez-Alier, 2014). Burada yine bireylerin kendi çıkarları söz konusu iken her iki kuramında biyosentrik bir çevrecilik içerdiğini söylemek kolay değildir. Inglehart'ın söz ettiği çevrecilik küresel anlamda oluşan kaygıyı içerirken, Martinez-Alier'in ifade ettiği çevreciliğin yerel bir tehdit karşısında oluştuğu söylenebilir. Martinez-Alier'in söylemlerine uygun olarak Mohai ve Bryant (1998) da çevre duyarlılığı konusundaki açıklamalarını bireylerin sosyal sınıfına ve ani ortaya çıkan çevre sorununa (Environmental Deprevation) bağlamışlardır.

\section{Antroposentrizm / Biyosentrizm (Ekosentrizm)}

Bu noktada Mohai ve Bryant’ın (1998) “ani çevre yıkımları” tanımı, çok tartışılan antroposentrizm/biyosentrizm kavramlarını irdelememize yardım edecektir. Antroposentrizm, odağa insanı alıp "her şeyin insan için" olduğu düşüncesine sahip bir yaklaşımdır. Bu yaklaşıma sahip olan insanların çevre duyarlılığının yüksek olması beklenemeyeceği gibi insanı merkeze alan bireylerin doğayı hoyratça ve kendi yararına kullanabilme olasılığı yüksektir. Antroposentrik anlayışa sahip kişilerin çevreyi koruma 
eğilimleri olduğu iddia edilse bile bu yaklaşımın insan yaşam kalitesini yükseltmek ve insanlığın devamını korumak için olduğu söylenebilir. Kısaca bu kişilerin doğaya karşı davranışları pragmatist ya da fırsatçı olarak tanımlanabilir. Antroposentrizm tek başına insan merkezli bir çevre anlayışını ifade etse de bu kavramın politik, kültürel ve ekonomik bağlantıları bulunmaktadır. Kısaca bireyin hangi sosyal tabakadan geldiği çevreye karşı duyarlılığ konusunda son derece önemlidir. Biyosentrizm ise antroposentrizmin tam tersi, insanı doğanın bir parçası olarak görür ve antroposentrizmi reddeder. Her canlının eşit hakka sahip olduğu düşüncesi üzerinde temellenir (Merchant, 1992). Bu anlayışa sahip bireylerin çevreyi koruma eğilimi ekosistemde yer alan tüm ögelerin devamlılı̆̆1 için önemlidir.

\section{Yeni Çevre Paradigması (NEP) / Baskın Sosyal Paradigma (DSP)}

Postmateryalizm kavramına paralel olarak çevreye karşı duyarlılık Dunlap ve Van Liere (1978) tarafından hazırlanan Yeni Çevre Paradigması (NEP) adlı anket ile sıklıkla kullanılmıştır. Farklı toplumlarda, farklı gruplarda uygulanmış ve zaman içinde de anket revize edilmiştir. NEP özellikle yükselen orta sınıfa ait ekosentrik çevre eğilimine vurgu yapmaktadır. Dünya kaynaklarının sınırlılığı üzerinden hareket eden NEP sürdürülebilir ve sürdürülemez dünya ikilemini ortaya koymaktadır. Van Liere ve Dunlap (1980) çevreye karşı duyarlılığı bireylerin geldikleri sınıf ve temel yaşam gereksinimleri ile ilişkilendirmeyi de ihmal etmemişledir. NEP anketi çevreye karşı duyarlı olanların yanında bir de baskın sosyal hareketleri takip edip tüketim toplumunu temsil eden ya da bu gruba katılma telaşı içinde olan bireylerin değer yargılarını da içermektedir. Donati (1996) bunu Baskın Sosyal Paradigma (DSP) olarak tanımlamaktır. Bu noktada aynı yukarıdaki antroposentrizm ve biyosentrizm karşıtlığında olduğu gibi karşımıza NEP ve DSP karşıtlı̆̆ı çıkmaktadır. Yeni Çevre Paradigması ile postmateryalist kuram da tanımladıkları değer yargıları açısından birbirleriyle örtüşmektedirler (Taşkın, 2009). Bu bölümde adı geçen tanımlar araştırmanın açıklayıcı kuramsal çerçevesini oluşturmaktadır.

\section{Yöntem}

\section{Çalışma Grubu}

Bu araştırma Karadeniz bölgesinde bir üniversitede 2015-2016 bahar döneminde "Çevre Bilinci ve Teknolojik Atıklar" adlı seçmeli dersine katılan Bilgisayar ve Öğretim 
Teknolojileri Eğitimi (BÖTE) 4. sınıf öğrencileriyle yürütülmüştür (N=50). Çalışma nitel araştırma tekniğine dayalı olup tartış, çiz ve yaz tekniğine göre yürütülmüşsür. Çalışma grubu kolay ulaşılabilir örneklem yöntemiyle oluşturulmuştur (Patton 2014, s. 242).

\section{Dersin İşlenişi ve Verilerin Toplanması}

Verilerin toplanması aşamasından önce Tablo 1'deki ders içeriği 13 hafta süresince uygulanmıştır. Ders işleme aşamasında öğrencilerin tartışmalara katılmasına olanak sağlanmış ve realist eğitim formatı kullanılmıştır. Kısaca, dersin işlenişinde kanıta dayalı ders yaklaşımı tercih edilmiştir. Muğaloğlu, Can ve Ceyhan (2017) yazdıkları bölümde kanıta dayalı ders yaklaşımın önemi hakkında dünya literatüründen örnekler vermektedirler. Dersin bu tarz işlenmesinin, örneklerin kanıtlar dahilinde sınıfa getirilmesinin iki nedeni bulunmaktadır. Bunlardan ilki sınıftaki öğrenci sayısının fazla olması, ikincisi ise ders saati süresinin haftada yalnızca 2 saat olmasıdır. Dersin işlenişi sırasında güncel olaylar kullanılırken veriler üzerinden hareket edilmiştir. Örneğin, 1950'den günümüze mera arazi varlığı ve aynı tarihten itibaren nüfus artışı arasındaki ilişkiye bakılmıştır. Bu yapılmadan önce toplam mera alanları ve nüfus yıllara göre verilmiştir. Değinilen konuya bakıldığında içerisinde konuşulacak ve ilişkilendirilebilecek terimlerden bazıları şunlardır: Kullanılabilir tarım alanı ve meralar, taşıma kapasitesi, sürdürülebilirlik kavramı, enerji akışı, popülasyon dinamiği, yetersiz beslenme vb. Konu hakkında veriler ortaya konulduktan sonra sistematik olarak sorular sorulmaktadır. Mera ve nüfus arasındaki ilişkiden çıkarımlarınız nelerdir? (Genel tartışma) Bu ilişkide beklenilen sonuçlar ne olabilir? (Projeksiyon) Otun ete dönüşmesi ya da enerji akışı açısından bu ilişkiyi tanımlar mısınız? (Değerlendirme). Can (2017) yüksek lisans tezinde, bu tarz öğretime “Kanıta Dayalı İnteraktif Öğretim” adını vermektedir.

Uygulama aşamasında ise ilk olarak katılımcılardan 3-4'er kişilik çalışma grupları oluşturmaları istenmiştir. Her gruptan yaşamak istedikleri çevreyi ve çizimde yer alacak öğeleri aralarında tartışarak resmetmeleri istenmiştir. Daha sonra çizimlerde kullandıkları her bir öğeyi neden resmettiklerine ilişkin yazılı ifadelerini doküman olarak sunmaları sağlanmıştır.

\section{Verilerin Analizi}

Çalışma verilerinin analizinde içerik analizi kullanılmıştır. İçerik analizi, birbirine benzer verilerin belirli temalar ve kodlar içerisinde yorumlama işidir (Yıldırım ve Şimşek, 
2008 s.228). Çizimler analiz edilirken katılımcıların yazılı anlatımlarından yararlanılmıştır. Katılımcıların kendi aralarında yaptıkları tartışmalara araştırmacılar müdahil olmamıştır ve veri analizi sürecine dahil edilmemiştir. $\mathrm{Bu}$ çalışmada kodlar ve temalar çizimlerin bitiminden sonra oluşturulmuştur. Daha net bir ifade ile nitel araştırmanın doğasına uygun olarak çizimlerdeki kodlar ve temalar tümevarımsaldır (Patton, 2014). Bunun yanı sıra çalışmanın verileri antroposentrizm/biyosentrizm ve Yeni Çevre Paradigması (NEP)/ Baskın Sosyal Paradigma (DSP) kavramları eşliğinde ve Postmateryalist teorik çerçeve içinde analiz edilmiştir ki, bu yaklaşım ise tümdengelime dayanmaktadır. İçerik analizinin katı teorik çerçeve kullanmama yaklaşımı Strauss ve Corbin aracılığı ile "gömülü teoriye" aitken; bu baskın postmodernist yaklaşımın aksine Elo ve Kyngäs (2008) hem tümevarım hem de tümdengelim yaklaşımın içerik analizi için kullanılabileceğini ifade etmektedir.

\section{Geçerlilik ve Güvenilirlik}

Temalar kodlara ve kuramsal çerçeveye uygun olarak seçilmiştir. Tema ve kodlar iki ayrı araştırmacı tarafından değerlendirilmiştir. Tema ve kodlar katılımcıların hem çizimlerinden hem de yazılı belge olarak sundukları metinler incelenerek oluşturulmuştur (Bakınız Tablo 2). Araştırmanın iç ve dış tutarlılığı hiçbir öğe kod dışında bırakılmayarak sağlanmıştır (Yıldırım \& Şimşek, 2008 s.259).

Tablo 1. Uygulanan ders saati ve içeriğin haftalara göre dağılımı.

\begin{tabular}{|c|c|c|c|}
\hline Hafta & & Ders Saati & İçerik \\
\hline 1. Hafta & $\begin{array}{l}\text { Çevre eğitimi }(C ̧ E) \\
\text { terimi ve tarihi } \\
\text { gelişimi }\end{array}$ & $45+45$ & ÇE, ekoloji ve çevre bilimi nedir? \\
\hline 2. Hafta & $\begin{array}{l}\text { Çevre Tutum, } \\
\text { Davranış ve Bilinci }\end{array}$ & $"$ & $\begin{array}{l}\text { Çevre tutumu, davranışı, bilinci, algısı ve } \\
\text { okuryazarlığı kavramları } \\
\text { Sürdürülebilirlik kavramı } \\
\text { Antroposentrizm ve biyosentrizm kavramı } \\
\text { Hayvan hakları }\end{array}$ \\
\hline 3. Hafta & ÇE Temel Amaçları & " & $\begin{array}{l}\text { Tiflis Konferansı, Brundtland raporu, Sessiz Bahar ve } \\
\text { biyosidler, Çevre Etki Değerlendirmesi }\end{array}$ \\
\hline 4. Hafta & $\begin{array}{l}\text { Popülasyon } \\
\text { Ekolojisi }\end{array}$ & " & $\begin{array}{l}\text { Popülasyon, tür, taşıma kapasitesi, habitat, niş, } \\
\text { popülasyon yoğunluğu, popülasyon dinamiği, } \\
\text { üreme tipleri, yaş piramitleri }\end{array}$ \\
\hline 5. Hafta & Komünite Ekolojisi & “ & $\begin{array}{l}\text { Simbiyosizm (mutualizm, kommensalizm, } \\
\text { protokooperasyon, avcılık ve rekabet) } \\
\text { Süksesyon, kilit tür, baskın tür, habitat parçalanması }\end{array}$ \\
\hline 6. Hafta & Ekosistem Ekolojisi & $"$ & $\begin{array}{l}\text { Biyom, ekoton, beslenme ve besin kavramları } \\
\text { Enerji piramidi, net primer üretim, biyolojik birikim, }\end{array}$ \\
\hline
\end{tabular}


biyomagnifikasyon

7. Hafta Ekosistem Ekolojisi

8. Hafta Ekosistem Ekolojisi

9. Hafta Vize Sinavı

10. Hafta Toprak Kirliliği

11. Hafta Su Kirliliği

13. Hafta Hava Kirliliği

14. Hafta Uygulama
Besin zinciri ve besin ağ

Enerji akışı, popülasyon dinamiği, beslenme düzeyleri ve kimyasal döngüler arasındaki ilişki Azot döngüsü; mineralizasyon, amonifikasyon, nitrifikasyon, denitrifikasyon kavramları

Fosfor döngüsü

Kükürt döngüsü

Su döngüsü

Karbon ayak izi, ekolojik ayak izi

Rizosfer tanımı ve toprak yapan etmenler

Toprağın yapısı

Erozyon-Ormansızlaşma

Kullanılabilir tarım alanı ve meralar

“ Saprobiyen basamakları ve su kalitesi BOİ (biyolojik oksijen ihtiyacı), KOİ (kimyasal oksijen ihtiyacı ve ÇO (çözünmüş oksijen) Ötrofik \& oligotrofik su (ötrofikasyon süreci)

Göl kirliliği ve katmanları

Isıl kirlenme

Su ayak izi

“ Lokal, bölgesel ve küresel kirlenme

Kirletici kaynakları

Ozon bozulması

Sera etkisi

Asit yağışları

Küresel iklim değişikliği önermeleri

Resim çizimi ve yazılı dokümanların toplanması

\section{Bulgular}

Katılımcıların çizimleri incelendiğinde yer verdiği öğelere ilişkin bulgular aşağı $d a$ verilmiştir.

Tablo 2. Katılımcıların çizimlerinde yer alan temaların kodlara göre dağılımı.

\begin{tabular}{lll}
\hline Temalar & Kodlar & Kullanılma sıklı̆̆ı \\
\hline & Deniz & 13 \\
& Tarım Alanı & 12 \\
& Orman & 7 \\
Doğal Alanlar & Çiftlik & 6
\end{tabular}


Göl

Piknik Alanı

Canlı Öğeler Hayvanlar (köpek, at, besi hayvanları, kuşlar, Arılar) 7

Bitkiler (Palmiyeler, çiçekler) 2

$\begin{array}{ll}\text { Yollar } & 35\end{array}$

$\begin{array}{ll}\text { Cami } & 28\end{array}$

AVM 22

$\begin{array}{ll}\text { Apartmanlar } & 21\end{array}$

$\begin{array}{ll}\text { Devlet Daireleri } & 19\end{array}$

Güvenlik Birimleri (Polis, Jandarma, Özel Güvenlik) 18

Okullar (İlkokul, Ortaokul, Lise, Üniversite) 16

Lüks konutlar (Villa, Gökdelen vb.) 11

$\begin{array}{ll}\text { Yenilenebilir Kaynaklar } & 11\end{array}$

$\begin{array}{lll}\text { Yapay Alanlar Otel } & 10\end{array}$

Sağlık Alanları 9

Otopark 9

Kafe- Bar (1) 9

Banka 8

Stadyum- Spor Alanı $\quad 8$

$\begin{array}{ll}\text { Fabrikalar } & 8\end{array}$

Adliye $\quad 8$

Müze $\quad 5$

Diğer İbadethaneler $\quad 5$

Kütüphane (3) 5

Havaalanı 5

Dershane ve Kurs 4

Mezarlık 4

Opera ve Tiyatro Salonları 3

Huzurevi 3

Kitapçı 3

Lunapark 3 
Yenilenemez Kaynaklar (nükleer santral)

Kiraathane

Döviz bürosu

Pet Shop

Külliye

Veteriner

Hayvan Barınağ1
3

3

2

2

2

Çizimlerdeki öğeler; doğal alanlar, canlı ögeler ve yapay alanlar olmak üzere üç tema altında toplanmıştır. Tablo 2 incelendiğinde canlı öğe kullanımının son derece sınırlı olduğu görülmektedir.

Canlı öğelerin sıkça kullanıldığı çizimler biyosentrik olarak düşünülse de katılımcıların kendi gereksinim duydukları canlılara yer verdikleri görülmektedir. Çizim 1'de katılımcılar çevrelerinde hayal ettikleri canlıların bulunmasını istediklerinden söz etmişlerdir. Yine benzer şekilde çizim 2' de canlı öğeler ağaçlık alan ve av köpeği ile sınırlıdır. Katılımcılar çizimlerinde tarım alanlarına sıklıkla yer verdikleri görülmektedir.

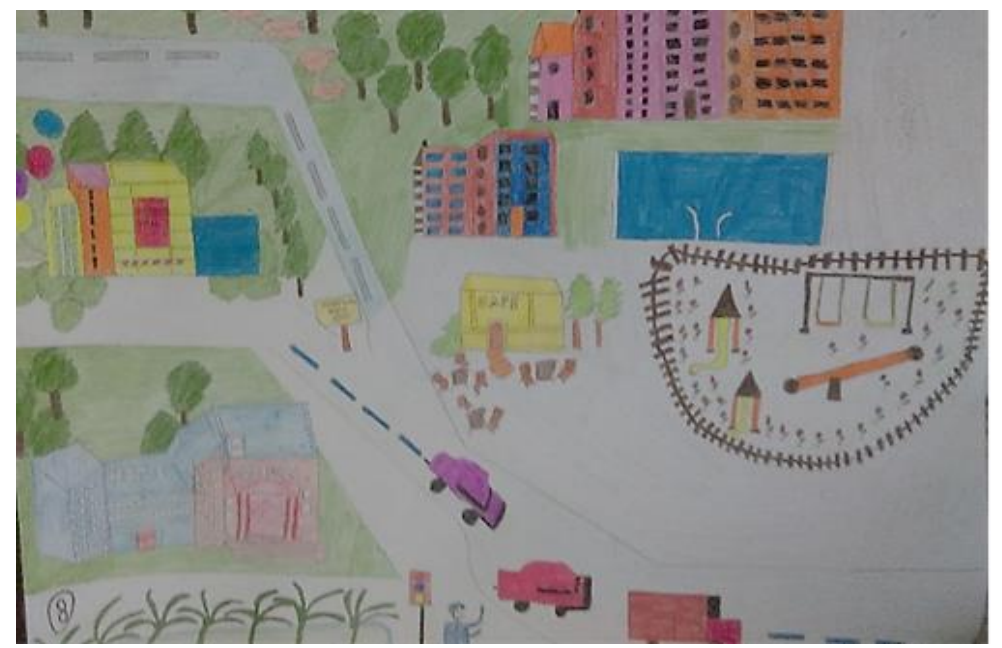

Çizim 1

“...Illk olarak kamu kuruluşlarının merkeze yakın olmasını istedik. Kent merkezinin güzel görünmesi için kaldırıma ağaçlar yerleştirdik. Hayal ettiğimiz insanları, kuşları vb. canlıları çevreye yerleştirdik. Yaşamak istediğimiz ev tek katlı bahçesi olan evler. Evlere ait yüzme havuzları bulunmakta. Çizimde doğa ve modernliği iç içe kullanmaya çalıştık. İnsanların eğlenmeleri ve alışveriş yapabilmeleri gerekli 
olduğu için bölgeye AVM dahil ettik. Doğa ile iç içe olduğu için ormanda otlayan kuzular ve yol kenarmda palmiyeler var."

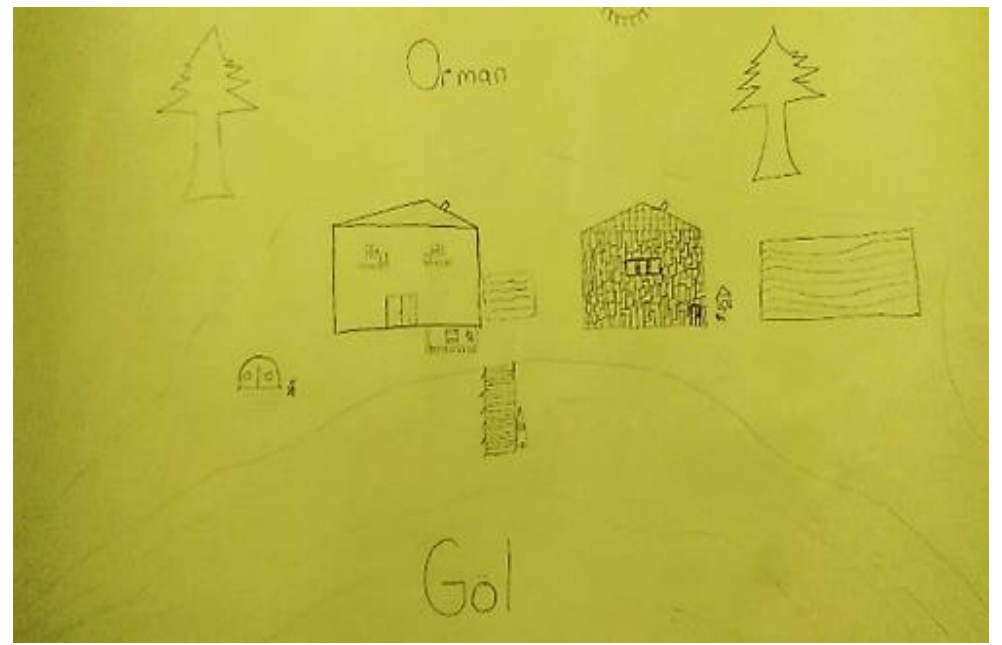

Çizim 2

"Biri ahşap diğeri beton olmak üzere iki adet göl evi var. Göl evinin arkası tamamıyla orman balık tutmaya yarayacak iskelemiz var. Ahşap evin yanında av köpeğimiz var..."

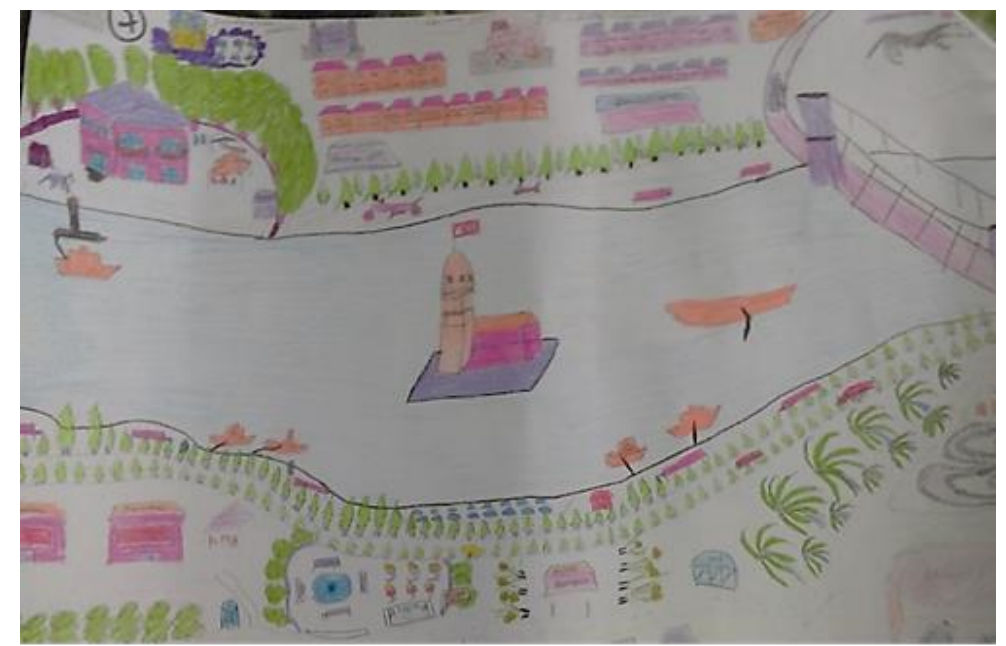

Çizim 3

"Hayalim İstanbul'da yaşamak ama şu anki hali değil. Öğretmen olacağım için okulum yanımda. Ailem ramazanda gelirse ibadet yapabilmek için evin yakınında cami var. Kız kulesini ve köprüyü çok seviyorum o yüzden çizdim. At çiftliğim var. Ata binmek ve atım olmasını çok istiyorum. AVM'leri sevmem fakat gerekli olduğu için onu da ekledim."

Çizimlerde sinema, tiyatro, eğlence alanlarına sık rastlanmazken hemen hemen her çizimde AVM karşımıza çıkmaktadır. Çizim 1'deki katılımcılar AVM'yi eğlence mekânı 
olarak değerlendirirken, çizim 3'deki katılımcılar AVM'leri sevmemesine rağmen gerekli olarak düşündüğü için çizdiklerini belirtmişlerdir. Akıncı (2013) çalışmasında orta-orta üst gelir grubundan gelen gençlerin boş zaman olarak nitelendirdikleri vakitlerini en çok AVM'lerde geçirdikleri sonucuna ulaşmıştır. AVM'leri tercih etme nedenleri sıralandığında \%50'ye yakını ulaşım kolaylığı ve tasarım açısında tercih ettiklerini söylerken, ikinci olarak da güvenlik ve sosyal ortamı dikkate aldıkları ifade etmektedir.

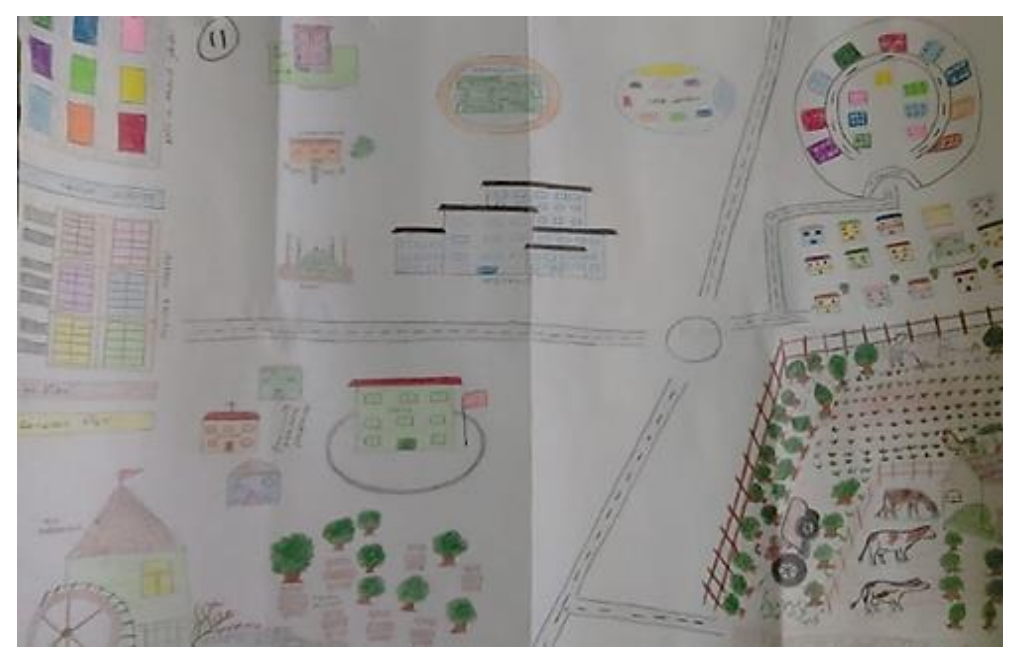

Çizim 4

“Üniversite çıkışında öğrencilerin yerleşebilecekleri siteler var. Bu sitenin aşağııında çiftlik yer alıyor. Her ülkeden arkadaşlar olduğu için cami ve diğer inanç yerleşimleri bulunuyor. Öğrencilerin kafa dağıtabileceği AVM'ler var."

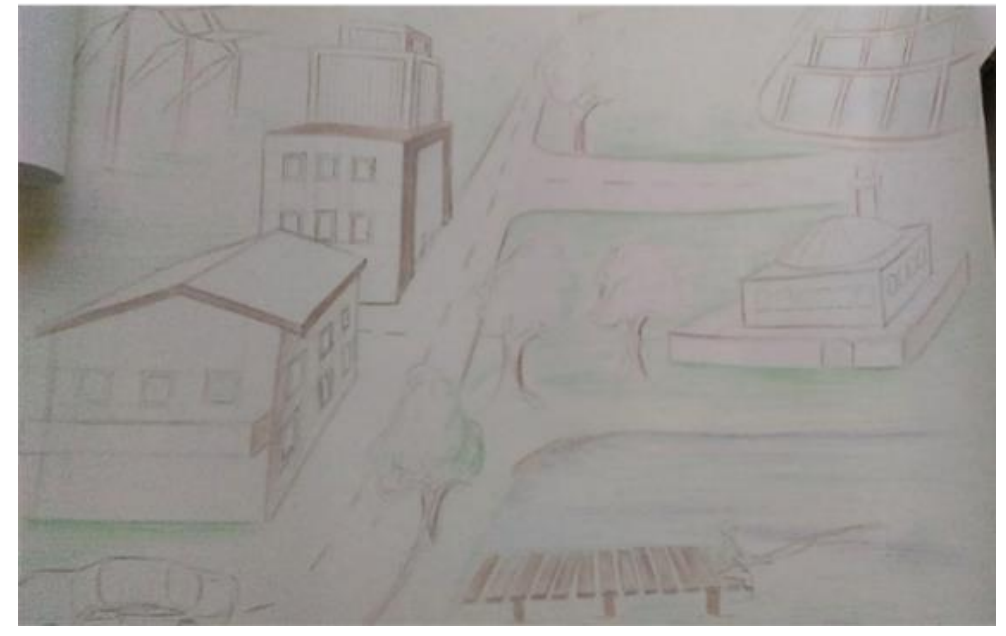

Çizim 5

"Yaşam ortamının doğal olmasını istedik şehir hayatından uzak ama kopuk değil. Elektrik ihtiyacı güneş panelinden ve rüzgâr tribünlerinden karşılamak istedik. Yaşam alanının bireysel ihtiyaçlara 
uygun olması sebebi ile ibadet yapabileceğimiz camimiz ve boş vakitler için mesire alanı hayal ettik. Yaşadığımız ev dubleks bahçesi olan ve iş merkezine yakın resmettik."

Çizimlerin birçoğu konut reklamlarında vaat edilen mahalleleri anımsatmaktadır. Çizimlerde sınırları belli, korunaklı, güvenli idealize edilmiş yaşam alanları mevcuttur. Katılımcıların çizimlerinde keskin bir biçimde belirlenmiş sınırlar dikkat çekmektedir. Sınırlar çoğu kez yollarla ya da ağaçlarla belirlenmiş olup bireylerin yaşadıkları konutların (siteler, villa, dubleks evler, apartmanlar, gökdelenler) birbirinden ayrıldığı görülmektedir. Çizimlerde orman, tarım alanları gibi doğal öğeler yaşam alanlarından ayrıştırılıp; işyerleri ve sosyal alanlar ise farklı sınırlar içerisinde konumlandırılmıştır. Yücebaş (2013, s. 24) toplumsal sınıflar ve tercih edilen mekanlar arasındaki ilişkiyi incelediği araştırmasında sınırları şu şekilde ifade ediyor; "sınır, düzenli olanın nerede kurgulanmış olduğunu belirler. Sınırın öte tarafı, düzensiz ve güvensizdir. Sınırlar, kategorileştirmenin bir uzantısıdır."

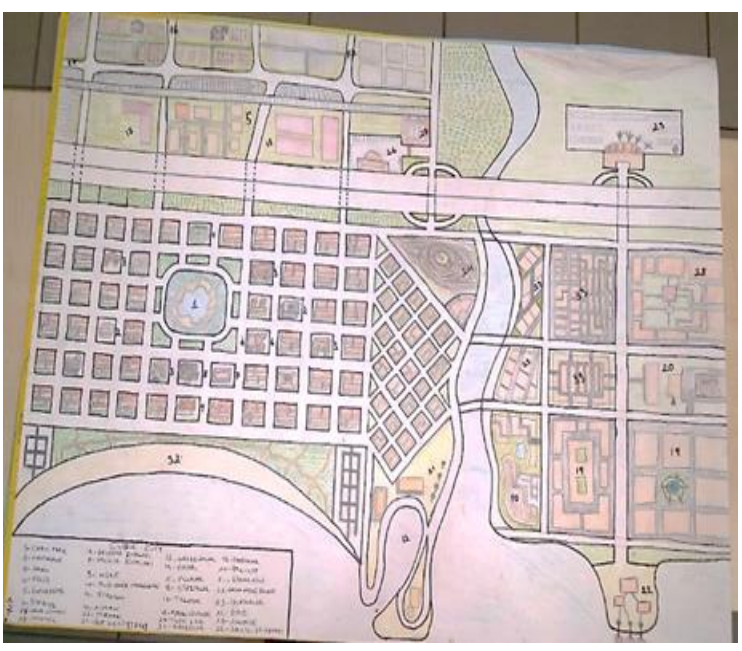

Çizim 6

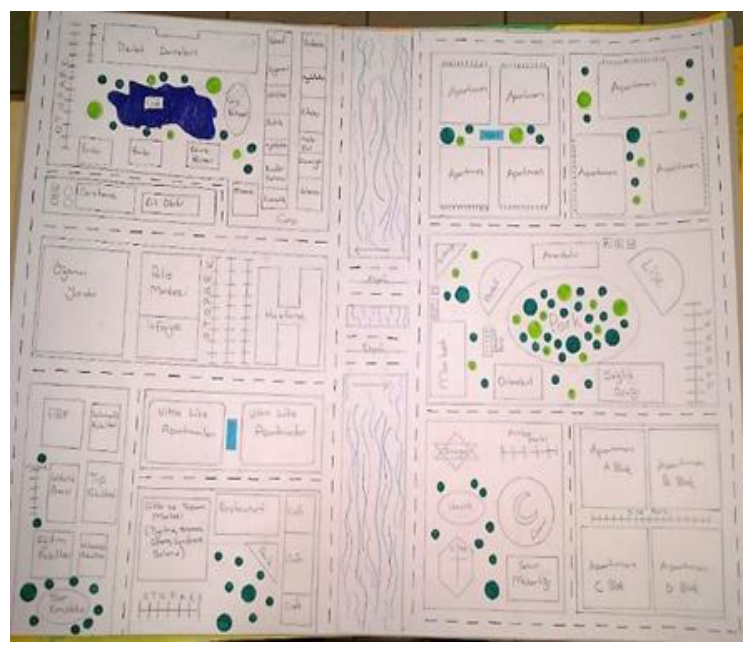

Çizim 7

Genellikle çizimlerde müstakil evler ile villalar diğer apartman ve sitelerden ayrı konumlandırılmış şekilde yer almaktadır. Daha önce sayı bakımından az olduğu belirtilen sinema, tiyatro ve eğlence alanlarının lüks olan yapıların etrafında konumlanması dikkat çekmektedir. Öte yandan kapalı siteler orta ve üst gelir grubundan insanların izole ve özel güvenlikli yaşam alanlarını temsil etmektedir. Yaşam tarzı, sosyal ve kültürel farklılıklar etrafında kümelenen insanlar, kendilerini toplumun geri kalanından ayırmak ve onlar için statü göstergesi olarak görülen konutlar, belirli konumlarda bu yönde şekillenir (Taşkın, 2016). Çizimlerin tamamında polis, jandarma, emniyet, karakol gibi güvenlik birimlerinin haricinde çizilen sitelerin içerisinde yer alan özel güvenlikler de mevcuttur. 


\section{Tartışma ve Sonuç}

Araştırmada kullanılan teori ve kavramlar çerçevesinde bulguları değerlendirdiğimizde katılımcıların büyük bir kısmının postmateryalist ve Yeni Çevre Paradigmasının öngördüğü değerlere yakın olmadığı sonucunu çıkarmak mümkündür. Örneğin, katılımcılar için bireysel güvenlik sorunu yaşanmak istenilen çevrede önemli bir parametre olarak ortaya çıkmaktadır. Çizimlerde en çok resmedilen ve yaşanmak istenilen çevrenin bir parçası olarak görülen AVMler ise güvenli bir sosyalleşme alanı olarak algılanmakta ve ilginç bir şekilde "kafa dağıtma" mekânı olarak tanımlanmaktadır. Baykal ve Denli $(2017$, s.54) reklam filmleri üzerinde yaptıkları çalışmada bu durumu şöyle ifade etmektedirler "İdealize edilen bu yeni yaşamda, alışveriş ve AVM kaçınılmaz bir yere sahiptir. Söz konusu site reklamlarında, AVM'nin var oluşu, pek çok sosyal imkânın, hatta evin kendisinin bile önüne geçer." Buna ek olarak çizimlerdeki kütüphane, müze ve tiyatro gibi sosyal etkinlik alanlarının sayısının azlığı katılımcıların postmateryalist değerlerle örtüşmediğinin göstergesi olarak karşımıza çıkmaktadır. Yine AVM kültürünün benimsenmesi tüketim toplumunun en güzel örneklerinden olup bireyin sınıfsal aidiyetinin simgesidir (Özgür, 2006). Buna ek olarak katılımcıların baskın sosyal paradigma değerlerine ait tüketici toplum özellikleri gösterebilecekleri de söylenebilir.

Katılımcılar çizimlerinde yaşam alanlarını sosyal statülere göre villa, güvenlikli site, dubleks evler, apartman ve gökdelen şeklinde ayırt etmektedirler. Bu durum Yücebaş'ın (2013) araştırmasında özellikle 1980 sonrası neoliberal politikaların sonucu olarak sunulmaktadır. Yücebaş bu farklı gettolaşmaların özellikle yoksulluğun gözden 1rak tutulmasına bağlamaktadır. Çizimlerdeki var olan sınırlar Yücebaş'ın araştırmasında ifade ettiği durumla uyuşmaktadır. Katılımcıların çoğu farkında olarak ya da olmayarak varsıl ve daha az varsılların yaşam alanlarını ayırt etmektedirler. Bunun yanında yaşam alanı olarak kendisine dubleks ev tercihinde bulunan katılımcılar da bulunmaktadır. İster gettolaşmayı onaylasın isterse kendisi için lüks yaşam alanı tercih etsin bireyler her iki tercihte de postmateryalist ya da Yeni Çevre Paradigmasının değer yargılarına sahip oldukları söylemek olası değildir. Ancak katılımcıların gettolaşmayı içselleştirilerek resmetmeleri ayrı bir araştırma konusu olarak karşımıza çıkmaktadır.

Alan yazında yapılan çalışmaların çoğunda katılımcıların biyosentrik çevre tutumuna sahip olduğu ifade edilmesine rağmen bu araştırmada katılımcıların büyük bir kısmının antroposentrik tutuma sahip olduğu sonucu karşımıza çıkmaktadır. Çizimlerde canlı öğeler 
daha çok pragmatik bir yaklaşımla bulunmaktadır. Ancak bu canlı öğelerin de sayıları oldukça az ve yapay oluşumdur. Doğal alan olarak deniz ve tarım alanı en çok istenilen oluşumlardır “... Ormanda otlayan kuzu ve yol kenarında palmiye..." gibi isteklerin ise nasıl doğal bir ortam olduğu ise ayrı bir tartışma konusudur.

Alan yazın çalışmalarında sıklıkla Brundtland Raporu'na atıfta bulunulmasına rağmen raporda yer alan eşitlik ve çevre kavramları arasındaki ilişki çoğu kez göz ardı edilmektedir. Aynı şekilde katılımcıların da çevrelerini tanımlarken benzer konutlarda barınma ve canlı öğelerle iç içe yaşam istekleri gözlenmemektedir, aksine sınırlarla ayrılmış yaşam bölgeleri oluşturmakta ve ihtiyaç duydukları canlıları bu ortama dahil etme eğilimindedirler. Sınırları belli yaşam bölgeleri oluşturmaları sahip oldukları değerler açısından bireylerin postmateryalist olmadıklarına işaret iken; yine kendi yararlanacakları canlıları ortama katmaları ise biyosentrik olarak değerlendirilse bile pragmatik biyosentrik ya da antroposentrik olarak değerlendirmek daha uygundur. Ayrıca kültürleşme, sosyal güvence, anne baba eğitim durumu gibi konular üzerine yoğunlaşamadıkça ve müfredata etkin bir ÇE programı yerleştirilmediği sürece bireylerin kabul edilebilir çevre değerlerine sahip olmaları oldukça zordur. Umulan, bu çalışma bulgularının literatürde doğurduğu boşluğu tamamlaması diğer ÇE araştırmacılarını motive etmesidir.

\section{Bilgilendirme}

Bu çalışma 4- 7 Ekim, 2018 tarihleri arasında düzenlenen 4. Uluslararası Çağdaş Eğitim Araştırmaları Kongresinde sözlü bildiri olarak sunulmuştur.

\section{Kaynaklar}

Akıncı, G. M. (2013). Gençler ve alışveriş merkezleri (avm'ler): avm kullanım tercihleri hakkında bir alan çalışması. Megaron, 8(2), 87-96.

Alerby, E. (2000). A way of visualising children's and young people's thoughts about the environment: A study of drawings. Environmental Education Research, 6(3), 205-222.

Barraza, L. (1999). Children's drawings about the environment. Environmental Education Research, 5(1), 49-66.

Baykal, Z. \& Denli, N. (2017). İdealize edilen yeni yaşamın tanıdık yüzü: Korunaklıgüvenlikli konut sitelerinin reklam filmleri üzerine bir içerik analizi. Sosyoloji Araştırmaları Dergisi, 20(2), 49-88.

Bozdemir, H. \& Faiz, M. (2018). Öğretmen adaylarının çevreye yönelik ekosentrik, antroposentrik ve antipatik tutumları. Sakarya University Journal of Education, 8(1), 6175 . 
Can, Ş. N. (2017). Using a model-evidence link diagram to explore nuclear energy: The effects on seventh graders' risk perception and understanding of the issues. Yayımlanmamıs yüksek lisans tezi. Boğaziçi Üniversitesi, Sosyal Bilimler Enstitüsü, İstanbul.

Donati, P. (1996). Environmentalism, postmaterialism, and anxiety: The new politics of individualism. Badia Fiesolana, Italy: European University Press.

Dunlap, R.E., \& Van Liere, K.D. (1978). The new environmental paradigm. Journal of Environmental Education, 9 (4), 10-19.

Elo, S., \& Kyngäs, H. (2008). The qualitative content analysis process. Journal of Advanced Nursing, 62(1), 107-115.

Erten, S. \& Aydoğdu, C. (2011). Türkiyeli ve Azerbaycanlı öğrencilerde, ekosentrik, antroposentrik ve çevreye karşı antipatik tutum anlayışları. Hacettepe Üniversitesi Ĕ̆itim Fakültesi Dergisi, 41, 158-169.

Fleer, M. (2002). Curriculum compartmentalisation?: A futures perspective on environmental education. Environmental Education Research, 8(2), 137-154.

Halmatov, M., Sarıçam, H., \& Halmatov, S. (2012). Okul öncesi eğitimdeki 6 yaş çocukların çizdikleri çevre resimlerinin ve çevre kavramını algılayışlarının farklı değişkenlere göre incelenmesi. Uluslararası Sosyal Bilimler Eğitimi Dergisi, 2(1), 30-44.

Hart, P. \& Nolan, K. (1999). A critical analysis of research in environmental education. Studies in Science Education, 34(19), 1-69.

Inglehart, R. (1977). The silent revolution: Changing values and political styles among Western publics. Princeton, NJ: Princeton University.

Işık, E. \& Çetin, G. (2014) 11. sınıf öğrencilerinin yaşadıkları çevreye ilişkin görüşleri. Eğitim ve Öğretim Araştırmaları Dergisi 3 (2), 75-86.

Martinez-Alier, J. (2002), The environmentalism of the poor a study of ecological conflicts and valuation. Edward Elgar Publishing.

Martinez-Alier, J. (2014), The environmentalism of the poor. Geoforum, 54, 239-241.

Merchant, C. (1992). Radical ecology. New York: Routledge.

Mohai, P. \& Bryant, B. (1998). Is there a" race" effect on concern for environmental quality?. Public Opinion Quarterly, 67, 475-505.

Muğaloğlu, E. Z., Can, N. \& Ceyhan, G. (2017). Kanıta dayalı fen eğitimi: Model kanıt ilişki şeması. Mutlu Pınar Demirci Güler (ed.) Fen Bilimleri Öğretimi: Kuram ve Uygulama Örnekleri (255-274). Pegem

Özden, D. Ö. \& Özden, M. (2015). Çevre sorunlarına ilişkin öğrenci çizimlerinin incelenmesi. Pamukkale Üniversitesi Ĕ̆itim Fakültesi Dergisi, 37(1), 1-20.

Özgür, E. F. (2006). Sosyal ve mekânsal ayrışma çerçevesinde yeni konutlaşma eğilimleri: Kapalı siteler, İstanbul, Çekmeköy örneği. Planlama Dergisi, 4, 79-95.

Özen-Uyar, R. \& Yılmaz Genç, M. M. (2016). Okul öncesi dönem çocukların farklı çevre konularma yönelik ekosantrik ve antroposentrik tutumları. Journal of Human Sciences, 13(3), 4579-4594. 
Özsoy, S. \& Ahi, B. (2014). İlkokul öğrencilerinin geleceğe yönelik çevre algılarının çizdikleri resimler aracılığı ile belirlenmesi. Kuram ve Uygulamada Eğitim Bilimleri, 14(4), 15571582.

Karakaya, Ç. \& Çobanoğlu, E. O. (2012). İnsanı merkeze alan (antroposentrik) ve almayan (nonantroposentrik) yaklaşımlara göre eğitim fakültesi son sınıf öğrencilerinin çevreye yönelik bakış açıları. Türk Fen Ë̆itimi Dergisi, 9(3), 23-35.

Patton, M. Q. (2014). Nitel araştırma ve değerlendirme yöntemleri. (M. Bütün ve S. B. Demir, Çev. Ed.). Ankara: Pegem Akademi.

Pınar, E. \& Yakışan, M. (2017). İlkokul öğrencilerinin çevre kavramları ile ilgili çizimlerinin analizi. Trakya Üniversitesi Ĕ̆itim Fakültesi Dergisi, 8(1), 97-113.

Ramsey, C. E. \& Rickson, R. E. (1976). Environmental knowledge and attitudes. The Journal of Environmental Education, 8(1), 10-18.

Taşkın, Ö. \& Şahin, B. (2008). Çevre kavramı ve altı yaş okul öncesi çocuklar. Pamukkale Üniversitesi Ĕ̆itim Fakültesi Dergisi, 23(23), 1-12.

Taşkın, Ö. (2009). The environmental attitudes of Turkish senior high school students in the context of postmaterialism and the new environmental paradigm. International Journal of Science Education, 31(4), 481-502.

Taşkın, Ö. (2016). Çocuk, bilim ve teknoloji. (Ed. Evrim Genç Kumtepe). Eskişehir: Anadolu Üniversitesi. (Bölüm 6: Çevre Eğitimi sayfa 138-174).

Taşkın, Ö. \& Külcü, M.G. (2019). Türkiye'de çevre eğitimi araştırmalarının irdelenmesi: Yapılandırmacılık ya da kuramsız düşünme "indoktrinasyon" mu? Yaşadıkça Eğitim, 33(1), 33-46.

Van Liere, K.D., \& Dunlap, R.E. (1980). The social bases of environmental concern: A review of hypotheses, explanations and empirical evidence. Public Opinion Quarterly, 44 (2), 181-197.

Yavuz, M., Balkan Kıyıcı, F., \& Atabek-Yiğit, E. (2015). Ortaokul öğrencilerinin çevre ve çevre bilinci algısının çizim yöntemi ile incelenmesi. VI. Uluslararası Türkiye Eğitim Araştırmaları Kongre Tam Metin Bildirileri Kitabı, 1264-1272.

Yıldırım, A. \& Şimşek, H. (2008). Sosyal bilimlerde nitel araştırma yöntemleri (6. basım). Ankara: Seçkin.

Yücebaş, M. (2013). Orta sinıflar ve modern gettolarda ayrıcalıklı yaşam. İnsanbilim Dergisi, 2(1), 21-38. 